\title{
ARTIGOS
}

\section{CONSULTORIA COLABORATIVA A DISTÂNCIA EM TECNOLOGIA ASSISTIVA PARA PROFESSORES}

DAVID DOS SANTOS CALHEIROS • ENICÉIA GONCCALVES MENDES

\section{RESUMO}

O objetivo do estudo consistiu em avaliar um serviço de consultoria colaborativa - SCC - a distância em Tecnologia Assistiva - TA - para professores, utilizando abordagem qualitativa do tipo exploratório. As participantes foram seis professoras de alunos com paralisia cerebral - PC - e três consultoras em TA. Um ambiente virtual de aprendizagem foi construído para prestar consultoria e coletar os dados obtidos na forma de respostas a questionários para consultores e professores. Os dados foram tratados pela análise de conteúdo. As evidências indicam que o SCC revelou-se benéfico para a atuação das consultoras e professoras, bem como para os estudantes com PC. A contribuição desta investigação consiste em indicar mais uma possibilidade de serviço de apoio à escola inclusiva.

\section{EDUCAÇÃO ESPECIAL • FORMAÇÃO DE PROFESSORES • ENSINO A DISTÂNCIA • TECNOLOGIA ASSISTIVA}

\section{COLLABORATIVE DISTANCE CONSULTING IN ASSISTIVE TECHNOLOGY FOR TEACHERS}

\section{ABSTRACT}

The objective of this study was to evaluate a collaborative distance consulting service - CDCS - in assistive technology - AT- for teachers using qualitative exploratory approach. The participants were six teachers of students with cerebral palsy - CP and three consultants in AT. A virtual learning environment was built to provide consultancy and to collect data obtained in the form of responses to questionnaires for consultants and teachers. The data were processed by content analysis. The evidence indicates that the CDCS proved to be beneficial to the performance of consultants and teachers as well as students with CP. This research contribution is to present another possibility of service in support of inclusive school. 
Cette étude qualitative de type exploratoire vise à évaluer un service de consultation collaborative -SCC - à distance en Technologie d'Assistance - TA - pour les professeurs. Six professeures d'élèves atteints de paralysie cérébrale - PC - ainsi que trois consultantes en TA y ont participé. Un environnement virtuel d'apprentissage a été construit pour entreprendre ce travail de consultation et collecter les données des les réponses aux questionnaires soumis aux professeurs et aux consultants. Ces données ont ensuite été traitées par l'analyse de contenu. Les résultats montrent que le SCC s'est avéré bénéfique non seulement pour les activités des consultantes et des professeures mais aussi pour les étudiants atteints de PC. La contribution de cette étude est de montrer une possibilité alternative de service de support à l'école inclusive.

\section{ÉDUCATION SPECIALE • FORMATIONS DES ENSEIGNANTES • ÉDUCATION A DISTANCE • TECHNOLOGIE D'ASSISTANCE}

\section{CONSULTORÍA COLABORATIVA A DISTANCIA EN TECNOLOGÍA ASISTIVA PARA PROFESORES}

RESUMEN

El objetivo del estudio consistió en evaluar un servicio de consultoría colaborativa -SCC- a distancia en Tecnología Asistiva -TA- para profesores, utilizando un abordaje cualitativo del tipo exploratorio. Las participantes fueron seis profesoras de alumnos con parálisis cerebral -PC- y tres consultoras en TA. Se construyó un ambiente virtual de aprendizaje para prestar consultoría y recoger los datos obtenidos bajo la forma de respuestas a cuestionarios para consultores e docentes. Los datos se trataron por medio del análisis de contenido. Las evidencias indican que el SCC se reveló benéfico para la actuación de las consultoras y profesoras, así como para los estudiantes con PC. La contribución de dicha investigación consiste en indicar otra posibilidad de servicio de apoyo a la escuela inclusiva. 
NECESSIDADE DE FORMAÇÃO ESPECIALIZADA EM TECNOLOGIA ASSISTIVA - TA é demanda frequente de professores de educação especial que buscam conhecimentos que possam auxiliá-los na implementação dos recursos dessa tecnologia no contexto educacional. Essa preocupação decorre do fato de que a TA é, em muitos casos, imprescindível ao processo de inclusão escolar para grande parcela de alunos do público-alvo da educação especial.

De acordo com a legislação norte-americana, a TA é entendida como recursos e serviços (U.S. GOVERNMENT, 2004). Os recursos são todo e qualquer item/produto feito em série ou sob medida para potencializar a participação social e a qualidade de vida das pessoas com deficiência. Os serviços são definidos como aqueles que auxiliam as próprias pessoas com deficiência a utilizar os recursos e, assim, os implementar em seu cotidiano.

Como se pode perceber, o conceito de TA não se resume essencialmente ao recurso em uma perspectiva horizontal; inclui também os serviços, permitindo o envolvimento e a atuação de profissionais de diferentes áreas do saber, de forma conjunta, visando à promoção da autonomia, independência, qualidade de vida e inclusão social de pessoas com deficiência (U.S. GOVERNMENT, 2004). Daí a importância de os professores especializarem-se nessa área e promoverem a inclusão escolar e social, utilizando-se da TA no seu espaço institucional. 
O Ministério da Educação - MEC - tem despendido alguns esforços no intuito de proporcionar formação continuada em TA para professores da educação básica, com foco naqueles que atuam em sala de recursos multifuncionais ${ }^{1}$ (BRASIL, 2009). Em geral, as formações oferecidas pelo MEC têm se dado em nível de aperfeiçoamento e de pós-graduação lato sensu, na modalidade a distância, na qual o campo da TA é apenas uma parte de vários conteúdos que são abordados na área de educação especial. Tal formação, porém, tem causado poucas mudanças nas práticas pedagógicas dos professores, que dão ênfase a conteúdos essencialmente teóricos e não estabelecem associação com as necessidades práticas e cotidianas do trabalho docente (FUMES et al., 2014).

A formação em serviço tem sido sugerida como alternativa para romper com a dissociação constituída entre os conteúdos teóricos e o campo prático. Para Nóvoa (2009) e Tardif (2011), o direcionamento da formação em serviço é para a solução de situações envolvendo problemas concretos do trabalho docente que, por sua vez, se relacionam ao processo de ensino-aprendizagem. Nessa perspectiva, os saberes científicos e pedagógicos devem emergir da própria prática docente, ao contrário da normatização antecipada de conteúdos que, com frequência, nos cursos de formação, é estabelecida pela universidade.

Na área da educação especial, o modelo da consultoria colaborativa tem se destacado por priorizar essa abordagem de prática centrada no serviço. De maneira específica, a consultoria colaborativa é uma estratégia destinada a resolver problemas educacionais relacionados ao processo de inclusão escolar. Esse trabalho envolve a participação colaborativa de profissionais especializados (por exemplo: terapeuta ocupacional, psicólogo, fisioterapeuta, fonoaudiólogo, assistente social, etc.) e professores da escola comum (MENDES; ALMEIDA; TOYODA, 2011). Na relação desses profissionais, a igualdade nos papéis de atuação deverá ser uma evidência e sob nenhuma hipótese deverá haver concentração do saber por determinada parte dos envolvidos com o processo de colaboração.

Tal proposta de serviço permite não somente a equiparação das oportunidades para os estudantes público-alvo da educação especial, ${ }^{2}$ mas também oportuniza a construção de habilidades profissionais de todos os envolvidos. Desse modo, mesmo a consultoria colaborativa sendo primariamente uma forma de prestação de serviço, traz a possibilidade de potencializar também a formação profissional em serviço para a inclusão escolar.

Os serviços de consultoria colaborativa oferecidos na área de TA para professores têm apontado resultados positivos e indicam que esses se apropriaram do uso desses recursos. Alpino (2008), por exemplo, investigou os efeitos da consultoria colaborativa entre um fisioterapeuta e professoras de cinco estudantes com paralisia cerebral - PC. O estudo

1 A SRM é um espaço que possui um conjunto de equipamentos de TA, informática, mobiliários, materiais pedagógico e de acessibilidade, destinados a apoiar a organização e a oferta do Atendimento Educacional Especializado para o público-alvo da Educação Especial, de forma complementar ou suplementar.

O público-alvo da educação especial é constituído por estudantes com deficiência, transtornos globais do desenvolvimento e altas habilidades/superdotação. 
foi realizado na cidade de Londrina, estado do Paraná, e para coletar os dados foram utilizados questionários, roteiros de entrevista e roteiro de observação. As ações centraram-se na acessibilidade dos estudantes à escola (ambiente, material escolar, atividades) e na capacitação específica das professoras. Os resultados indicaram ganho no desempenho dos estudantes nas atividades em sala de aula e também ações mais efetivas foram relatadas pelas professoras após terem participado do processo.

Lourenço (2012) avaliou os efeitos de uma proposta de formação em serviço sobre recursos de TA para professores e profissionais envolvidos com a escolarização de estudantes com PC em um estudo desenvolvido em uma cidade do interior do estado de São Paulo. Os dados foram coletados por meio de entrevistas em grupo, registros em diários de campo, questionários abertos e filmagens. Os resultados indicaram que a parceria colaborativa estabelecida entre terapeuta ocupacional, fonoaudiólogas e professoras de educação especial contribuiu para a resolução dos problemas educacionais, além de evidenciar a possibilidade viável de formação em serviço para professores na área de TA.

Hummel (2012) avaliou uma proposta de formação de professores na área de TA, num estudo realizado em um município do estado do Paraná. Os dados foram coletados por meio de questionários, observação e ficha de registro. A autora concluiu que a rede de apoio colaborativa no local de trabalho é indispensável para a formação do professor, uma vez que é no cotidiano do serviço que as incertezas e inseguranças se desencadeiam quanto à melhor forma de atender as necessidades educacionais dos estudantes.

Dounis (2013) analisou a atividade docente de uma professora em um processo de consultoria colaborativa para inclusão escolar de um estudante com PC. Participou da pesquisa uma professora da rede pública municipal de Maceió, estado de Alagoas, que tinha em sua sala de aula um estudante com PC. O SCC focou na prescrição e confecção de recursos de TA. Para coletar os dados, foram utilizadas entrevista reflexiva, observação colaborativa, videogravação e autoconfrontação simples. A autora concluiu que o processo da consultoria colaborativa e as autoconfrontações incidiram de forma positiva, confirmando a possibilidade do uso de ambos os procedimentos como estratégias de formação docente para a educação inclusiva.

No conjunto, os desfechos desses estudos identificam o potencial de resolução de problemas decorrentes da inclusão escolar, além do aspecto formativo em serviço da consultoria colaborativa. Entretanto, os estudos sinalizam também um grande desafio para a formação docente, que é o da continuidade no uso dos recursos de TA. Em geral, com o término da consultoria oferecida, ocorre também a descontinuidade no uso dos recursos de TA (HUMMEL, 2012; LOURENÇO, 2012). Como alternativa para solução desse problema, os pesquisadores têm recomendado 
a implementação de um serviço permanente de consultoria colaborativa na área de TA para professores, com a finalidade de estimular e garantir o uso continuado desses recursos em sala de aula.

Muito embora a consultoria colaborativa tenha sido ressaltada como importante à formação docente, é preciso pensar na configuração prática desse tipo de serviço, pois outros desafios emergem na medida em que se constata: 1) o número insuficiente de profissionais especializados em TA com conhecimentos relativos à área da educação e escola para atender à demanda dos professores (PENA; ROSOLÉM; ALPINO, 2008); 2) a ausência de incentivos governamentais para a contratação desses profissionais para atuar na rede básica de ensino regular (ROCHA, 2013); 3) o alto custo dos programas presenciais de formação (HACK, 2011; LEMOS; CARDOSO; PALACIOS, 2005).

Assim, no presente contexto, a modalidade a distância pode constituir-se em uma possibilidade relevante para o desenvolvimento de formação continuada em uma perspectiva de consultoria colaborativa, na medida em que oferece solução mais econômica e mais acessível, por permitir que consultores assessorem um maior número de professores no uso de TA, fornecendo ao mesmo tempo prestação de serviço e formação. Além do mais, como apontam Teixeira et al. (2010), a formação a distância favorece o espaço de forte dinamicidade e interatividade.

Assim, considerando que os professores podem apropriar-se da usabilidade dos recursos de TA, mas que ao mesmo tempo encontram dificuldades para usar de forma independente e autônoma esses recursos, e que existe a recomendação de consultoria colaborativa permanente no processo de formação docente, o presente estudo teve como objetivo avaliar os limites e possibilidades de um SCC a distância em TA para professores de SRM, como apoio à inclusão escolar de estudantes com PC.

\section{METODOLOGIA}

A pesquisa realizada é de abordagem qualitativa com enfoque exploratório (SAMPIERI; COLLADO; LÚCIO, 2006).

\section{PARTICIPANTES}

Participaram da pesquisa seis professoras que atuavam em SRM nos municípios de Maceió, estado de Alagoas, e Rio Claro, estado de São Paulo. Todas possuíam formação em cursos de licenciatura e pós-graduação lato sensu na área de educação especial e duas tinham concluído mestrado na área de Educação. Também participaram dessa pesquisa três consultoras em TA: duas com formação inicial em Terapia Ocupacional e uma graduada em Fisioterapia e Pedagogia. Todas as consultoras possuíam pós-graduação stricto sensu na área de educação especial, sendo 
que duas eram doutoras e a terceira estava com o doutoramento em curso. O critério de seleção baseou-se na amostra intencional não probabilística. ${ }^{3}$ Todas as participantes assinaram o Termo de Consentimento Livre e Esclarecido - TCLE.

\section{AMBIENTE DA PESQUISA}

Considerando que a construção do ambiente virtual de pesquisa envolveria conhecimentos especializados na área de informática, foi contratada uma designer instrucional. Em seguida, deu-se início à busca por selecionar o ambiente virtual disponível no mercado que melhor respondesse às necessidades do desenho metodológico da pesquisa. $\mathrm{O}$ ambiente selecionado foi o Moodle, adaptado às características da pesquisa, sendo denominado de CTA, sigla do termo ConsulTecAssistiva.

De maneira geral, o ambiente CTA foi pensado tendo como base a facilitação do acesso à informação, a facilidade para a comunicação entre as professoras e as consultoras (com intermediação do pesquisador), a facilidade do acesso às orientações a fim de permitir o envio e organização de materiais que auxiliam a consultoria, bem como a facilitação da comunicação entre as próprias consultoras. Para atender a essas premissas, o ambiente CTA apresenta uma variedade de ferramentas (recursos e links para arquivo ou website, tarefa, bate-papo, fórum, dentre outros), envolvendo múltiplas funções de compartilhamento de arquivos e de recursos textuais e multimídia, bem como mecanismos para a comunicação, execução e acompanhamento de tarefas.

Em relação ao aspecto estrutural, o ambiente CTA foi organizado em duas partes especificadas a seguir: área de informações gerais sobre a pesquisa e área de operacionalização do SCC em TA.

- Área de informações gerais sobre a pesquisa

Na área de informações gerais sobre a pesquisa foram disponibilizados às participantes os principais informes (carta convite, informações sobre o projeto e TCLE) considerados essenciais para o início do envolvimento na pesquisa.

- Área de operacionalização do serviço de consultoria colaborativa em TA

Essa área foi configurada de forma a proporcionar às professoras de SRM uma sequência de etapas, no intuito de lhes fornecer melhor entendimento da dinâmica de implementação desse serviço. Em síntese,

Esse tipo de amostragem desconsidera a fundamentação matemática ou estatística, dependendo unicamente dos critérios subjetivos do pesquisador (GIL, 2008, p. 110) esse espaço permitia às professoras de SRM apresentarem suas demandas, interagirem com as consultoras de TA - por meio da mediação do pesquisador - para resolver as problemáticas, aplicarem as orientações, fazerem o feedback de suas aplicações e, por fim, avaliarem a prestação do serviço oferecido. 
Para auxiliar o processo de navegação no ambiente CTA e o devido uso das ferramentas, foi desenvolvido um vídeo tutorial (legendado) com orientações pormenorizadas.

O ambiente CTA teve seu conteúdo e formato avaliados por juízes (mestres e doutores na área de educação especial). O período de construção/adequação do ambiente virtual da pesquisa durou cerca de dois meses, mas seu aperfeiçoamento se fez durante todo o período de realização da pesquisa.

\section{INSTRUMENTOS DE COLETA DE DADOS}

Foram utilizados dois instrumentos de coleta de dados:

- Questionário sobre Demanda de Caso para Consultoria Colaborativa a Distância em TA - DCC-TA:

O Questionário DCC-TA foi elaborado pelos pesquisadores e teve seu conteúdo avaliado por juízes. A finalidade desse instrumento foi conhecer as dificuldades que as professoras de SRM tinham em relação ao uso da TA na escolarização de estudantes com PC. Trata-se de instrumento autoadministrável, contemplando perguntas abertas e fechadas, e foi agregado ao ambiente CTA para que os participantes pudessem respondê-lo.

- Questionário de Avaliação Final do SCC a Distância em TA - AFCC:

$\mathrm{O}$ AFCC foi elaborado pelos pesquisadores e submetido à validação de conteúdo por juízes. O intuito do AFCC foi avaliar o processo final de intervenção. Em termos técnicos, esse questionário é autoadministrável (contemplando perguntas abertas e fechadas) e foi incorporado ao ambiente CTA para ser respondido pelas professoras e consultoras.

\section{PROCEDIMENTOS DE COLETA DE DADOS}

Inicialmente, foi solicitado às professoras de SRM que respondessem ao DCC-TA via ambiente CTA. Em seguida, teve início o serviço, o qual envolveu quatro casos de estudos ${ }^{4}$ formados por dois casos individuais (Professora 1 e Professora 2) e por dois casos de duplas (Dupla 1 e Dupla 2). Cada um dos casos deveria selecionar um estudante com PC que demandasse o uso de recurso de TA, descrever as necessidades desse estudante e realizar registros por meio de vídeos e fotos para análise das consultoras. Esses dados foram postados no ambiente CTA.

Em seguida, cada caso foi analisado pelas três consultoras que ofereceram sugestões sobre indicação e implementação de recursos de TA. Posteriormente, as consultoras definiram com cada professora ou duplas de professoras qual recurso implementar para o caso de seu estudante.

Depois de definida a implementação, as consultoras utilizaram-se de instruções a distância, escritas ou audiovisuais, sobre como ensinar o estudante a utilizar o recurso selecionado. As professoras de SRM implementaram as recomendações e registraram suas tentativas confundir com o termo "estudo de caso", que remete a um método de investigação científica. 
de implementação por meio de relatos e filmagens e as postaram no ambiente CTA. Esses registros foram analisados pelas consultoras que ofereceram feedback do desempenho das professoras.

Todo o processo de colaboração estabelecido entre as consultoras e professoras foi mediado pelo pesquisador principal dessa pesquisa.

Ao final da intervenção - que durou oito meses -, ocorreu o processo de avaliação das ações desse serviço prestado, por meio do Questionário AFCC.

\section{ANÁLISE DE DADOS}

Os resultados obtidos foram tratados por meio da técnica de análise de conteúdo, especificamente a temática (BARDIN, 2011). Para aplicá-la, foi feita leitura flutuante dos materiais recolhidos a fim de identificar os temas importantes para o estudo. Em seguida, houve exploração dos potenciais de codificações baseados em critérios temáticos que favoreceu a formulação de cinco categorias temáticas, a saber:

- benefícios para os alunos estudados;

- benefícios para atuação profissional;

- pontos positivos da consultoria a distância;

- pontos negativos da consultoria a distância;

- $\quad$ sugestões dadas ao serviço de consultoria.

Essas categorias temáticas serão debatidas na seção Resultados e Discussão.

\section{ASPECTOS ÉTICOS}

Esta pesquisa foi aprovada pelo Comitê de Ética em Pesquisa da Universidade Federal de São Carlos - UFSCar -, campus São Carlos, estado de São Paulo, por meio do protocolo n. 349.028/2013, e os princípios éticos, descritos na Resolução n. 466/2012 (BRASIL, 2012), foram seguidos com diligência.

\section{RESULTADOS E DISCUSSÃO}

Os resultados alcançados nesta pesquisa foram organizados em cinco categorias que são discutidas a seguir.

\section{BENEFÍCIOS PARA OS ALUNOS ESTUDADOS}

Avaliação das professoras

Pelo fato de as professoras terem sido as únicas profissionais responsáveis por implementar as recomendações/sugestões do processo de consultoria, apenas suas opiniões foram tomadas para análise nessa categoria.

Assim, quando indagadas se seus alunos haviam sido beneficiados, as professoras em conformidade responderam que sim. Em alguns 
casos, os benefícios alcançados para os estudantes foram além de suas expectativas. Confira uma ilustração desse acontecimento:

\section{Partindo com objetos de sua realidade, de seu contexto e interesse pude obter respostas que antes acreditava que elas não existiam (Dupla 1).}

O benefício relatado pela Dupla 1 diz respeito ao sucesso obtido na comunicação com seu estudante que possuía dificuldades nessa área. Tal fato possibilitou a essa dupla, posteriormente, avançar no processo de escolarização do referido estudante. Esse resultado reafirma o efeito positivo da consultoria colaborativa, evidenciado nos estudos de Assis (2013) e Lourenço (2012), como proposta que beneficia o processo de escolarização dos estudantes público-alvo da educação especial.

Convém destacar que as recomendações estabelecidas no processo de consultoria não se restringiram ao ambiente da SRM e ao professor que nela atuava. Antes, foram compartilhadas com pais e professores de classe comum, ampliando as possibilidades de beneficiar os estudantes em outros contextos. Para exemplificar essa situação, apresenta-se o seguinte relato:

\section{As sugestões foram compartilhadas com os pais e professores da escola que o aluno estuda, ampliando as possibilidades de ação em relação à TA (Professora 2 ).}

Ademais, é relevante citar que os benefícios advindos do SCC contribuíram para o processo de escolarização de outros estudantes que não participaram do estudo. Veja:

A consultoria auxiliou até mesmo na resolução de problemas com outros alunos (Dupla 1).

Tal fato é visto como muito positivo, uma vez que demonstra que a abordagem das ações estabelecidas no SCC contribuiu para empoderar o professor e não apenas resolver as necessidades educacionais especiais de determinado estudante. De acordo com Mendes, Almeida e Toyoda (2011), o empoderamento faculta ao professor resolver problemas educacionais futuros com mais sensibilidade e habilidade, tomando como base os conhecimentos adquiridos e compartilhados em experiências anteriores com o modelo de prestação de serviços da consultoria colaborativa.

Em contraste a tudo isso está o caso da Dupla 2, a qual menciona que, embora seu estudante tenha sido beneficiado, esse benefício não foi plenamente satisfatório. Em sua concepção, apenas a problemática 
relacionada à adequação postural/posicionamento do estudante no uso do computador foi resolvida. As demais sugestões/recomendações dadas pelas consultoras explicam a referida dupla, apenas reforçaram suas práticas cotidianas com o estudante, não acrescentando conhecimentos novos que pudessem melhor auxiliá-lo. Veja:

Não foi plenamente satisfatório, pois não recebi orientações diferentes do que já faço [...]. Somente uma correção de posicionamento [no uso do computador] foi possível modificar na minha prática. Esperava um retorno um pouco maior. Porém, senti segurança e tranquilidade para continuar fazendo meu trabalho (Dupla 2).

Embora seja perceptível a tendência da Dupla 2 para compreender que os resultados não tenham sido tão satisfatórios para o caso do seu estudante, compete informar que as recomendações das consultoras foram importantes para que a referida dupla continuasse a desenvolver seu trabalho com segurança, o que também se compreende como benefício para o trabalho pedagógico com o estudante.

\section{BENEFÍCIOS PARA ATUAÇÃO PROFISSIONAL}

Avaliação das consultoras

Em conformidade com os princípios da consultoria colaborativa, todas as participantes envolvidas nessa proposta de prestação de serviços deveriam ser beneficiadas (KAMPWIRTH, 2003). No caso das consultoras, o benefício foi alegado por todas, sendo justificado da seguinte forma:

Sempre é um ganho poder refletir sobre práticas com o aluno com $\mathrm{PC}$, principalmente em formato colaborativo com outros profissionais (Consultora 1).

Compartilhar informações acerca da implementação de recursos de TA foi muito importante para reflexão de minha atuação profissional (Consultora 2).

Os casos trabalhados auxiliaram na minha formação e experiência profissional, em decorrência de ter que voltar na literatura e estudar mais sobre os assuntos específicos. A consultoria colaborativa por meio da parceria de três profissionais mais o pesquisador foi essencial para ter domínio sobre temas específicos da TA voltada para a educação especial (Consultora 3).

De acordo com os relatos das consultoras, os benefícios propiciados pelo SCC a distância em TA para suas atuações profissionais baseiam-se no fato de esse serviço possibilitar momentos de reflexão sobre a escolarização de estudantes com PC, compartilhamento de informações 
sobre a implementação de recursos de TA e a necessidade de retorno à literatura para aprofundar os conhecimentos sobre a área da TA no intuito de propor recomendações mais eficazes.

Muito embora a literatura internacional sobre consultoria colaborativa destaque que os benefícios desse modelo de prestação de serviços se remetam a todos os envolvidos - consultores, professores e estudantes (IDOL; NEVIN; PAOLUCCI-WHITCOMB, 2000; KAMPWIRTH, 2003) -, na literatura nacional a ênfase maior tem sido dada a investigar os benefícios relacionados aos professores e estudantes. Desse modo, o presente estudo permitiu investigar se os consultores também estavam sendo favorecidos (ou não) por meio dessa proposta de prestação de serviços de consultoria colaborativa.

Avaliação das professoras

Os resultados obtidos demonstraram que todas as professoras foram favorecidas em suas atuações profissionais por meio do SCC a distância em TA. Entre os benefícios assinalados, destacam-se: possibilidades de tirar dúvidas sobre o processo de escolarização de estudantes público-alvo da educação especial, possibilidades de reflexão profissional, oportunidades de experienciar novas propostas de intervenção envolvendo o uso da TA, colaboração com profissionais de áreas distintas e aprofundamento teórico sobre o campo da TA. Confira:

\begin{abstract}
Pude tirar dúvidas que tinha no trabalho com os meus alunos e melhorar a minha atuação profissional. [...] As orientações passadas fizeram com que eu refletisse sobre quais atividades iria propor ao meu aluno (Dupla 1).
\end{abstract}

Novas propostas de intervenção foram experienciadas (Professora 1).

Foi gratificante compartilhar dificuldades que são específicas do aluno e aprender com profissionais de áreas distintas, compreendendo que as sugestões instigam aprofundamento teórico na área da TA (Professora 2).

Como pode ser constatado nesses fragmentos, os benefícios advindos do SCC a distância em TA para a atuação profissional das professoras foram muito amplos e, em parte, assemelham-se aos benefícios encontrados no estudo de Lourenço (2012). Desse modo, os resultados alcançados com esta pesquisa permitem inferir que o SCC a distância em TA constituiu-se como importante instrumento de auxílio ao trabalho e à atividade docente. 
De acordo com os relatos das consultoras, os aspectos positivos do SCC a distância em TA estiveram relacionados a cinco pontos. O primeiro diz respeito à troca e compartilhamento de informações, bem como à vantagem de ter acesso a esses registros quando os participantes quisessem, já que todas as comunicações ficavam registradas no ambiente CTA. Confira:

Possibilidade de compartilhar situações e ideias (Consultora 1).

A troca de informações de forma que o registro pode ser acessado quando o professor quisesse (Consultora 2).

Uma das características principais da consultoria colaborativa é primar pela colaboração, conforme mencionam Mendes, Almeida e Toyoda (2011). Desse modo, por meio dos resultados apresentados, entende-se que o serviço proposto obteve sucesso nesse aspecto. Outras pesquisas que também se propuseram a oferecer serviços de consultoria colaborativa alcançaram resultados semelhantes (ASSIS, 2013; LOURENÇO, 2012).

O segundo aspecto positivo mencionado pelas consultoras trata-se do fato de o SCC proposto ter envolvido mais de um consultor, possibilitando atuação multidisciplinar. Veja:

Ter mais de um consultor participando [do serviço de consultoria colaborativa a distância em TA] (Consultora 2).

Possibilidade de trocas multidisciplinares (Consultora 1).

Essa atuação multidisciplinar tem sido recorrentemente destacada como importante por pesquisadoras da área da educação especial (DELLA BARBA et al., 2013; MENDES, 2011; TOYODA et al., 2007), na medida em que a inclusão escolar demanda conhecimentos muito especializados que estão além da atuação restrita de um único profissional, sobretudo da atuação do professor, que muitas vezes não obteve, durante sua formação inicial, conhecimentos acerca da escolarização do público-alvo da educação especial.

A potencialidade do SCC em capacitar professores e estudantes para o uso da TA também foi relatada como questão favorável:

A pesquisa teve muitos pontos positivos como, por exemplo, capacitar os professores por meio de ambiente virtual com a ajuda de profissionais com experiência na área de TA e instrumentalizar os alunos e professores no uso de recursos de TA (Consultora 3). 
Esse resultado corrobora a concepção de Mendes (2008), que entende a consultoria colaborativa como estratégia designada tanto para equacionar problemas relativos ao processo de escolarização do público-alvo da educação especial, quanto para promover o desenvolvimento das competências e habilidades profissionais dos professores.

O quarto ponto evidenciado como positivo faz menção ao ambiente CTA e destaca seu caráter autoilustrativo como fator que exerceu bom desempenho no SCC a distância em TA. Entende-se esse resultado como importante conquista, uma vez que esse aspecto influenciava diretamente na operacionalização da consultoria.

Destaca-se também, como aspecto positivo no SCC a distância em TA, a dinâmica conduzida pelo pesquisador durante o serviço proposto. Em linhas gerais, a forma de atuação do pesquisador baseava-se em mediar o contato entre as professoras e consultoras. Assim, em um primeiro momento, o pesquisador entrava em contato com as professoras para entender suas demandas na área da TA. Em seguida, era responsável por sintetizar as informações colhidas e encaminhá-las para as consultoras para que essas pudessem estudar o caso e orientar as professoras quanto às possíveis mudanças a serem executadas.

Depois que as consultoras faziam suas sugestões, o pesquisador novamente fazia a síntese desse material e repassava para as professoras para que essas analisassem a viabilidade de implementar as recomendações sugeridas. Quando as professoras questionavam ou não concordavam com as recomendações, o pesquisador coletava essas informações e as repassava para as consultoras, que faziam suas reconsiderações e davam novas possibilidades de ação.

Nos casos em que as professoras decidiam executar as recomendações, o pesquisador solicitava que registrassem o processo de implementação no ambiente CTA por meio de relatórios, fotos, vídeos, dentre outros. Esses registros eram colhidos pelo pesquisador, que fazia novamente o processo de síntese e o encaminhava para as consultoras que davam o feedback dessa implementação às professoras.

Convém destacar que, quando havia atraso nas respostas das consultoras ou das professoras, em qualquer etapa, o pesquisador entrava em contato com os participantes e agendava novos prazos para que cumprissem com as ações requeridas. 
Avaliação das professoras

Para as professoras, os pontos positivos do SCC a distância em TA assemelham-se, em certa medida, aos descritos pelas consultoras. O primeiro remete à possibilidade de contar com apoio e trocar conhecimentos com profissionais/consultores de áreas distintas e de realidades diferentes. Confira:

Orientações dos consultores (Dupla 2).

Contar com o apoio de profissionais de outras áreas. A troca de conhecimentos a partir de realidades tão distintas (Professora 2).

Mendes (2010) considera que a inclusão escolar prescinde de serviços de apoio para ter possibilidades de atender às necessidades educacionais dos estudantes público-alvo da educação especial. O SCC a distância em TA apresenta-se como possibilidade capaz de apoiar esse processo de inclusão escolar que muitas vezes é redimensionado apenas à figura do professor.

O segundo aspecto, considerado positivo pelas professoras, diz respeito ao fato de o SCC ter proporcionado diferentes possibilidades de uso da TA, conforme se pode constatar a seguir:

\section{A consultoria abriu um leque de possibilidades de se trabalhar com materiais facilitadores [recursos de TA] (Professora 1).}

Considera-se o fato de o SCC ter proporcionado às professoras inúmeras possibilidades de uso da TA como muito importante. Faz-se essa afirmação devido à literatura da área apontar que, em geral, os professores desconhecem a funcionalidade desses recursos, fato que justifica sua pouca utilização no contexto educacional (MANZINI, 2011). Assim, espera-se que, por meio desses resultados, as professoras participantes desta pesquisa possam utilizar os recursos de TA com mais frequência em seu cotidiano de trabalho, auxiliando a escolarização do público-alvo da educação especial.

O ambiente CTA também foi mencionado pelas professoras como elemento positivo, destacando-se, em especial, por proporcionar espaço de fácil entendimento e de interatividade entre as participantes. Confira: 
Diante desse resultado, compreende-se que o ambiente CTA atingiu seu intuito principal de facilitar a comunicação entre os participantes, o acesso à informação e a possibilidade de vivenciar práticas colaborativas.

Por fim, de acordo com o relato das professoras, destaca-se como relevante no SCC a distância em TA o papel do pesquisador, sobretudo por sua disponibilidade e atenção despendida. Veja:

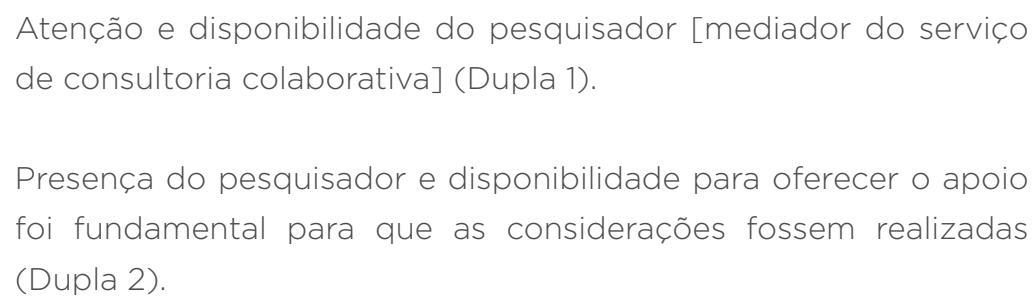

De maneira específica, a mediação exercida pelo pesquisador no ambiente CTA se deu no sentido de servir como elo de comunicação entre as professoras e as consultoras. Infere-se que essa atuação contribuiu para o desempenho das professoras no serviço em questão.

\section{PONTOS NEGATIVOS DA CONSULTORIA}

Avaliação das consultoras

De acordo com as consultoras, entre os aspectos negativos da consultoria colaborativa a distância em TA está a falta de dinamicidade do serviço oferecido. Para elas, a consultoria deveria ocorrer de forma mais intensa, havendo velocidade maior entre a postagem das professoras e o retorno das consultoras. Todavia, a impossibilidade de as consultoras estarem presente no ambiente CTA com mais frequência foi vista, por elas próprias, como aspecto limitante. O relato da Consultora 1 ilustra esse aspecto:

\footnotetext{
Destaco a minha impossibilidade de estar presente no ambiente, na frequência que julgo ter sido necessária, para contribuir com as demandas colocadas. Assim, acho importante a seleção dos consultores quanto à atribuição de tarefas, para que não prejudique a interação entre as parcerias. No ambiente virtual, penso que a velocidade entre a postagem e retorno deva ser bastante rápida e a disponibilidade dos consultores afeta diretamente essa questão.
}

No excerto supracitado, a Consultora 1 recomenda que seja feito um trabalho de seleção das consultoras, quanto às suas atribuições profissionais, para que a sobrecarga de seus respectivos trabalhos não venha influenciar no funcionamento do serviço. Entende-se que essa orientação é relevante, todavia tradicionalmente os trabalhos de 
consultoria colaborativa têm sido desenvolvidos por meio da ação voluntária de pesquisadores e estudantes da área da educação especial, que em geral não recebem por esse serviço, antes buscam reforçar a ideia de que a consultoria é modelo de prestação de serviços promissor que pode contribuir para a resolução de problemas educacionais (DELLA BARBA et al., 2013; TOYODA et al., 2007).

Para a consultoria colaborativa alcançar resultados ainda mais positivos é necessário que, antes de tudo, transcenda o campo da pesquisa e haja investimento por parte do poder público na contratação de profissionais especialistas (terapeuta ocupacional, fisioterapeuta, fonoaudiólogo, psicólogo, dentre outros), no intuito de que possam atuar no campo da educação por meio de ação colaborativa e, assim, proporcionar suporte mais eficaz à escola.

Para além do foco exclusivo nas consultorias, a Consultora 2 menciona que deve haver maior adesão, no serviço de consultoria, também por parte das professoras. Veja:

\section{A adesão mais sistemática [no serviço de consultoria colaborativa a distância em TA], tanto por parte das consultoras, como por par- te das professoras (Consultora 2)}

Nesse relato, a Consultora 2 poderia estar levando em consideração o fato de que, em dados momentos, as professoras não implementavam as sugestões, mesmo tendo concordado com as recomendações e terem firmado acordo em pô-las em prática. No estudo de Correia (2013), essa problemática também foi ressaltada e, segundo a autora, esse aspecto acontece devido à inexistência de cultura de colaboração, no âmbito da formação inicial de professores, que os faça entender que são eles os responsáveis pela mudança, cabendo aos consultores apenas o papel de auxiliar esse trabalho.

Outro aspecto considerado negativo pelas consultoras, especificamente pela Consultora 3 , diz respeito à impossibilidade de o SCC a distância em TA permitir auxílios em tempo real e sua limitação quanto à aproximação ao ambiente familiar dos estudantes. Confira:

\section{Como ponto negativo, destaco que um programa de consultoria a distância não permite auxílios em tempo real e aproximação com a família das crianças (Consultora 3).}

Em parte, a concepção da Consultora 3 é questionável, pois o SCC a distância oferecia ferramentas, dentre elas o chat, que possibilitava a comunicação em tempo real. Entretanto, sua utilização foi limitada na pesquisa devido à incompatibilidade de horários entre as participantes, por conta da restrição de tempo das consultoras e professoras, que 
não dispunham de muitos momentos para esse tipo de interação. Em relação à aproximação com a família, de fato entende-se como limitação da proposta desse serviço. Todavia, era necessário primeiro avaliar os limites e as possibilidades, dentro dos objetivos propostos dessa pesquisa, para que depois, em caso de sucesso, se pensasse em ampliar essa proposta de serviço para outros públicos e contextos.

Por último, compete informar que as consultoras revelaram o mau funcionamento da visualização dos vídeos ${ }^{5}$ no ambiente CTA como elemento negativo do SCC a distância em TA. Para solucionar essa problemática, o suporte técnico do ambiente CTA fez algumas recomendações que poderiam ser seguidas para melhorar o desempenho. Dentre as recomendações estavam: 1) verificar a conexão da internet - poderia estar lenta; e 2) trocar o navegador - Mozilla Firefox foi indicado como o mais eficaz. Por meio dessas orientações, foi possível diminuir as situações de travamentos dos vídeos.

Avaliação das professoras

Na concepção das professoras, a problemática maior em relação ao SCC a distância em TA consistiu no longo tempo de espera para receber o retorno das consultoras. Os relatos, apresentados a seguir, exprimem esse descontentamento:

\section{A demora nas devolutivas das consultoras [feedback do processo de consultoria] (Dupla 2).}

A demora [das consultoras] em responder as demandas apresentadas (Professora 2).

Essa questão já foi discutida, nos relatos das consultoras, como fator negativo. Desse modo, torna-se indispensável, ao propor um serviço de consultoria seja ele qual for, que os consultores tenham mais disponibilidade de tempo para colaborar, pois esse aspecto tem implicações diretamente no curso da consultoria.

Outro fator apontado como negativo pela Dupla 1 diz respeito ao desconhecimento do pesquisador ou das consultoras (a partir de visitas in loco) sobre o aluno sugerido para estudo na consultoria. Confira seu relato:

O pesquisador ou consultor não conhecer [a partir de visitas in loco] o aluno sugerido para o estudo (Dupla 1).

Muito embora se considere o fato de que foi possível avaliar a 5 distância as demandas docentes e, de maneira específica, as condições gerais dos estudantes e suas necessidades educacionais envolvendo o uso da TA, constata-se certa ênfase das professoras em primar por momentos em que o pesquisador ou consultor tenha possibilidade de

Houve complicações no ambiente CTA para baixar/visualizar os vídeos que as professoras postavam em relação ao processo de implementação da consultoria. 
conhecer o aluno também de forma presencial. Em linhas gerais, não se compreende esse aspecto como oposição à proposta de consultoria a distância, mas como outra forma de melhorar o funcionamento do SCC a distância em TA.

Por fim, destaca-se que a Dupla 2 mencionou outro aspecto negativo relacionado ao serviço de consultoria, dessa vez envolvendo seu caso em específico, que consistia na divergência entre as recomendações dadas pelas consultoras:

Divergência de orientação dos colaboradores [consultoras] (Dupla 2).

A divergência entre as recomendações das consultoras ocorreu como consequência do fato de elas terem posicionamentos diferentes para determinadas situações. Um exemplo dessa divergência pode ser constatado na ocasião em que uma parte das consultoras sugeriu associar os símbolos pictográficos (comunicação alternativa) com Libras e a outra discordava dessa associação para favorecer a comunicação do estudante da Dupla 2 e seu processo de alfabetização. Assim, pensou-se que apresentar essas duas perspectivas, mesmo sendo distintas, poderia tornar a Dupla 2 mais ativa no processo de consultoria, no sentido de que pudesse escolher quais caminhos trilhar. Porém, para esse caso, pode não ter sido favorável a adoção dessa medida, pois a dupla demandou uma única solução.

\section{SUGESTÕES DADAS AO SERVIÇO DE CONSULTORIA}

Sugestões das consultoras

As consultoras apresentaram três sugestões a fim de aprimorar o funcionamento do SCC a distância em TA. A primeira diz respeito ao formato de participação das professoras no serviço em questão. De acordo com a Consultora 2, esse deveria acontecer em duplas, em vez de individual. Confira esta sugestão:

Acredito que o formato de professoras em dupla foi mais satisfatório (Consultora 2).

Ainda que não tenha sido a finalidade do presente estudo investigar qual a melhor forma de participação das professoras, se individual ou em duplas, durante o processo de consultoria, o formato em duplas proporcionou resultados mais satisfatórios, uma vez que estimulou o processo de colaboração entre as próprias professoras na resolução de problemas, no planejamento e nas práticas e estratégias pedagógicas.

A segunda sugestão refere-se à possibilidade de ampliar o quadro de consultoras do SCC a distância em TA. Também considerada favorável, pelo fato de que uma quantidade maior de consultores poderia proporcionar um suporte mais eficaz e divisão da responsabilidade 
desse processo de escolarização do público-alvo da educação especial envolvendo o uso da TA. No entanto, faz-se a ressalva da relevância de os consultores serem de áreas e de especialidades diferentes, já que surgem demandas muito amplas e diversificadas durante o SCC a distância em TA.

A última sugestão identificada no relato das consultoras remete à possibilidade de acontecerem encontros presenciais na escola-alvo da consultoria como forma de conhecer o contexto de atuação e complementar as informações necessárias para a operacionalização do SCC a distância em TA. Confira:

Se fosse possível, pelo menos, uma ida presencial na escola dos
consultores e pesquisador seria muito interessante, até mesmo
para redimensionar os espaços, perceber a realidade da professo-
ra, os materiais disponíveis. Então, a consultoria seria a distância
com híbrido de pelo menos um encontro presencial (Consultora 2).

Quanto à realização de encontros presenciais, compreende-se que não há problemas, até porque, tradicionalmente, a consultoria vem sendo realizada na modalidade presencial e os resultados têm sido satisfatórios (ALPINO, 2008; LOURENÇO, 2012; PEREIRA, 2009; SILVA, 2010). Também não se entende essa recomendação como característica indicativa de insucesso do SCC a distância em TA, mas como mais uma forma de potencializar o serviço prestado, no sentido de atender eficazmente as reais necessidades do contexto escolar.

Sugestões das professoras

Nos relatos das professoras constataram-se duas sugestões que poderiam melhorar a operacionalização do SCC a distância em TA. A primeira enfatizou a necessidade de tornar esse serviço mais rápido em suas ações, oferecendo uma devolutiva imediata às demandas das professoras. Para tanto, houve indicação de utilização de recursos tecnológicos que promovessem a comunicação em tempo real, como Skype e chat. ${ }^{6}$ Veja:

As devolutivas acontecerem de forma mais rápida (Dupla 1).

Acredito que o uso de Skype, chat [...] e outros [recursos tecnológicos de comunicação em tempo real] irá aperfeiçoar ainda mais o serviço (Professora 2).

Sobre esse assunto, Brito (2003) declara que a característica principal da modalidade a distância é a possibilidade de se manter, de forma fácil e rápida, a interação entre seus interlocutores - no caso do presente estudo, entre consultoras e professoras. Por esse motivo, concorda-se das ferramentas disponíveis para uso no ambiente CTA, mas percebe-se que sua presença foi desconhecida entre os participantes. 
com as professoras de que o SCC a distância em TA deva tornar-se mais rápido em suas ações, mesmo que para isso faça uso mais intenso de tecnologias como chat, Skype, Hangout ou WhatsApp. Segundo Brito (2003), para utilizar essas referidas tecnologias de interações mais sincronizadas, tanto as consultoras como as professoras devem estar conectadas no mesmo instante. Assim, com determinadas ferramentas, seria importante agendar horários, em virtude da dificuldade de coincidir momentos em comum nas agendas dos participantes para esse tipo de interação.

A segunda sugestão diz respeito à importância em compreender melhor a realidade docente a partir de visitas in loco. Confira:

É preciso compreender melhor a realidade dos professores (Dupla 2).

Como sugestão, penso que seria muito importante que o consultor ou pesquisador fosse até a escola para conhecer o aluno mencionado, para que o professor pudesse relatar o trabalho já desenvolvido e a partir desse relato o serviço de consultoria iniciar (Dupla 1).

Tal ponto também foi recomendado pelas consultoras como relevante indicando a necessidade de se investir nessa mudança. Em geral, prima-se que o SCC a distância em TA possa atender, com mais sensibilidade, às condições e necessidades do contexto educacional local e, de maneira específica, às necessidades do estudante-alvo da consultoria, no intuito de alcançar os objetivos visados.

\section{CONSIDERAÇÕES FINAIS}

As evidências encontradas indicam que o SCC a distância em TA atingiu resultados importantes, uma vez que os estudantes com PC foram beneficiados por meio das ações implementadas. No entanto, eles não foram os únicos favorecidos, já que a consultoria permitiu resolver problemas educacionais de outros estudantes por meio do empoderamento docente. Ademais, o SCC também se revelou benéfico para a atuação profissional das consultoras e professoras da pesquisa.

Desse modo, a contribuição desta investigação consiste em indicar mais uma possibilidade de serviço de apoio que deve estar disponível em um contínuo de serviços para favorecer a construção de escolas inclusivas.

Como sugestão para estudos futuros, faz-se menção de determinadas recomendações. Uma delas diz respeito à necessidade de compreender melhor a realidade docente e dos estudantes para que as consultorias prestadas sejam potencializadas, dando ênfase a tecnologias que possibilitem comunicação em tempo real. Outra sugestão 
imprescindível remete-se ao critério de seleção das consultoras. Deve-se dar preferência àquelas com expertise nas áreas da demanda da consultoria que tenham disponibilidade de tempo e interesse em prestar esse tipo de serviço a distância. No presente estudo, as consultoras tinham outros compromissos e eram voluntárias na pesquisa; seria diferente se fossem profissionais especialmente contratadas para esse tipo de serviço.

Destaca-se, assim, ser importante estabelecer parcerias intersetoriais entre as redes de saúde, educação e outras interessadas, de modo que a consultoria colaborativa faça parte das incumbências de atuação dos profissionais dessas áreas, desvirtuando-se do exercício da ação puramente voluntária.

Por fim, destaca-se que a política de escolarização de estudantes do público-alvo da educação especial requer a construção de redes de serviços de apoio à escola que ainda não estão disponíveis em nossa realidade. Especificamente no caso dos estudantes com PC, as famílias que optam pela escola comum muitas vezes veem-se privadas de serviços de reabilitação e do apoio de equipes multiprofissionais, uma vez que não há provisão desses serviços nas escolas comuns ou mesmo, na maioria dos municípios, nos serviços públicos. Assim, além da sobrecarga financeira que a busca por esses serviços fora do sistema público representa, esses atendimentos acabam comprometendo a frequência de muitas crianças à escola comum porque, além de financeiramente custoso, acabam concorrendo pelo tempo disponível na agenda atribulada dos estudantes e de suas famílias com os mais variados tipos de atendimentos necessários para sanar/minimizar as necessidades da condição da deficiência.

Assim, embora os serviços de profissionais de equipes multiprofissionais sejam indispensáveis para muitos alunos do público-alvo da educação especial, ainda há no país considerável resistência em relação à contratação de tais profissionais com verbas da área de educação sob a alegação de que tais profissionais são da área da saúde. Entretanto, há que se ressaltar que esses profissionais podem ser formados para atuar em diferentes contextos e que se eles ainda não têm visão educacional é porque o mercado de trabalho que os absorve ainda é o da área da saúde; e é para eles que as universidades têm formado.

O presente estudo investigou os limites e possibilidades da consultoria colaborativa escolar de profissionais de equipe multiprofissional, no caso de terapeutas ocupacionais e fisioterapeutas, para apoiar a implementação de recursos de TA, que são indispensáveis na escolarização de estudantes com PC. Os resultados demonstram que esse tipo de serviço tem potencial para resolver problemas e prover formação em serviço e, além disso, que tais resultados podem ser maximizados se esse modelo for associado ao modo presencial de prestação de serviço. Como implicação, sugere-se investigar como financiar esses serviços, fazê-los chegar às escolas e formar profissionais para atuar no contexto educacional. 


\section{REFERÊNCIAS}

ALPINO, Ângela. Consultoria colaborativa escolar do fisioterapeuta: acessibilidade e participação do aluno com paralisia cerebral em questão.2008. 191f. Tese (Doutorado em Educação Especial) Universidade Federal de São Carlos, São Carlos, 2008.

ASSIS, Caroline. Formação de terapeutas ocupacionais em consultoria colaborativa na escola: avaliação de um programa online. 2013. 169 f. Tese (Doutorado em Educação Especial) - Universidade Federal de São Carlos, São Carlos, 2013.

BARDIN, Laurence. Análise de conteúdo. São Paulo: Edições 70, 2011.

BRASIL. Ministério da Educação. Programa de formação continuada de professores na educação especial - modalidade à distância. Brasília: MEC, 2009.

BRASIL. Resolução n. 466, de 12 de dezembro de 2012. Aprova as diretrizes e normas regulamentadoras de pesquisas envolvendo seres humanos. Diário Oficial da União, Brasília, DF, 12 dez. 2012. Disponível em: <http://conselho.saude.gov.br/resolucoes/2012/Reso466.pdf>. Acesso em: 23 jun. 2014.

BRITO, Mário. Tecnologias para a EAD via internet. In: ALVES, Lynn; NOVA, Cristiane. (Org.). Educação \& tecnologias: trilhando caminhos. Salvador: Uneb, 2003. p. 61-87.

CORREIA, Daniela. A percepção dos docentes da educação regular e da educação especial sobre a sua prática colaborativa inclusiva na educação pré-escolar e no ensino básico. 2013. 199f. Dissertação (Mestrado em Ciências da Educação) - Escola Superior de Educação João de Deus, Lisboa, 2013.

DELLA BARBA, Patrícia et al. Necessidades de familiares de crianças com necessidades educacionais especiais em relação ao seu processo de inclusão escolar. Revista Digital, Buenos Aires, v. 17, n. 177, p. 1-5, 2013.

DOUNIS, Alessandra. Atividade docente e inclusão: as mediações produzidas pela consultoria colaborativa. 2013. 180f. Dissertação (Mestrado em Educação) - Universidade Federal de Alagoas, Maceió, 2013.

FUMES, Neiza et al. A formação continuada de professores de salas de recursos multifuncionais do município de Maceió/AL. Revista Teias, Rio de Janeiro, v. 14, n. 35, p. 71-87, 2014.

GIL, Antonio. Métodos e técnicas de pesquisa social. 6. ed. São Paulo: Atlas, 2008.

HACK, Josias. Introdução à educação à distância. Florianópolis: LLV/CCE/UFSC, 2011.

HUMMEL, Eromi. Formação de professores das salas de recursos multifuncionais para o uso da tecnologia assistiva. 2012. 231f. Tese (Doutorado em Educação) - Universidade Estadual Paulista, Marília, 2012.

IDOL, Lorna; NEVIN, Ann; PAOLUCCI-WHITCOMB, Phyllis. Collaborative consultation. 3. ed. Austin, Texas: Pro- ED, 2000.

KAMPWIRTH, Thomas. Collaborative consultation in the schools: effective practices for students with learning and behavior problems. New Jersey: Merril Prentice Hall, 2003.

LEMOS, André; CARDOSO, Claudio; PALACIOS, Marcos. Revisitando o projeto Sala de Aula no século XXI. In: ARAÚJO, Bohumila; FREITAS, Katia (Org.). Educação a distância no contexto brasileiro: algumas experiências da UFBA. Salvador: ISP/UFBA, 2005. p. 9-29.

LOURENÇO, Gerusa. Avaliação de um programa de formação sobre recursos de alta- tecnologia assistiva e escolarização. 2012. 258f. Tese (Doutorado em Educação Especial) - Universidade Federal de São Carlos, São Carlos, 2012.

MANZINI, Eduardo. Formação de professores e tecnologia assistiva. In: CAIADO, Katia; JESUS, Denise; BAPTISTA, Claudio (Org.). Professores e educação especial: formação em foco. Porto Alegre: Mediação, 2011. v. 2, p. 45-63.

MENDES, Enicéia. Alta TA \& inclusão: viabilizando o uso de recursos de alta tecnologia assistiva na escolarização de alunos com disfunções motoras. Brasília, 2008. Projeto de Pesquisa financiado pelo CNPq. 
MENDES, Enicéia. Observatório Nacional de Educação Especial: estudo em rede nacional sobre as salas de recursos multifuncionais nas escolas comuns. Brasília, 2010. Projeto de Pesquisa Observatório da Educação, edital n. 38/2010 Capes/Inep.

MENDES, Enicéia. A formação do professor e a Política Nacional de Educação Especial no Brasil. In: CAIADO, Katia; JESUS, Denise; BAPTISTA, Claudio (Org.). Professores e educação especial: formação em foco. Porto Alegre: Mediação, 2011. v. 2, p. 131-146.

MENDES, Enicéia; ALMEIDA, Maria; TOYODA, Cristina. Inclusão escolar pela via da colaboração entre educação especial e educação regular. Educar em Revista, Curitiba, v. 41, p. 80-93, 2011.

NÓVOA, António. Para uma formação de professores construída dentro da profissão. In: NÓVOA, António. Professores: imagens do futuro presente. Lisboa: Educa, 2009. p. 25-46.

PENA, Flávia; ROSOLÉM, Fernanda; ALPINO, Ângela. Contribuição da fisioterapia para o bemestar e a participação de dois alunos com distrofia muscular de Duchenne no ensino regular. Revista Brasileira de Educação Especial, Marília, v. 14, n. 3, p. 447-462, 2008.

PEREIRA, Veronica. Consultoria colaborativa na escola: contribuições da psicologia para inclusão escolar do aluno surdo. 2009. 164 f. Tese (Doutorado em Educação Especial) - Universidade Federal de São Carlos, São Carlos, 2009.

ROCHA, Aila. Recursos e estratégias da tecnologia assistiva a partir do ensino colaborativo entre os profissionais da saúde e da educação. 2013. 210 f. Tese (Doutorado em Educação) - Universidade Estadual Paulista, Marília, 2013.

SAMPIERI, Roberto; COLLADO, Carlos; LUCIO, Maria. Metodologia de pesquisa. 3. ed. São Paulo: McGraw-Hill, 2006.

SILVA, Aline. Psicologia e inclusão escolar: novas possibilidades de intervir preventivamente sobre problemas comportamentais. 2010. 258f. Tese (Doutorado em Educação Especial) Universidade Federal de São Carlos, São Carlos, 2010.

TARDIF, Maurice. Saberes docentes e formação profissional. 12. ed. Petrópolis: Vozes, 2011.

TEIXEIRA, Adriano et al. Como o ciberespaço coloca fim à educação a distância. In: MACHADO, Glaucio (Org.). Educação e ciberespaço: estudos, propostas e desafios. Aracaju: Virtus, 2010. p. 182-207.

TOYODA, Cristina et al. O contexto multidisciplinar da prática da terapia ocupacional frente ao paradigma da inclusão escolar. Cadernos de Terapia Ocupacional da UFSCar, São Carlos, v. 15, n. 2, p. 121-130, 2007.

U.S. GOVERNMENT. Public Law 108-364, 25 Oct. 2004. Assistive Technology Act of 2004. 108th Congress. U.S. Government Publishing Office, Washington, DC, 25 Oct. 2004. Disponível em: <http://www.gpo.gov/fdsys/pkg/STATUTE-118/pdf/STATUTE-118-Pg1707.pdf>. Acesso em: 17 jan. 2016.

\section{DAVID DOS SANTOS CALHEIROS}

Mestre em Educação Especial pela Universidade Federal de São Carlos - UFSCar -, São Carlos, São Paulo, Brasil

david_calheiros@yahoo.com

\section{ENICÉIA GONÇALVES MENDES}

Professora adjunta da Universidade Federal de São Carlos - UFSCar -, São Carlos, São Paulo, Brasil

eniceia.mendes@gmail.com 